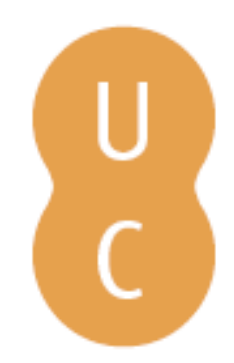

\title{
nombalina
}

\section{Processos de construção não concatenativa}

Autor(es): $\quad$ Pereira, M. Isabel P.

Publicado por: Imprensa da Universidade de Coimbra

URL

persistente: URI:http://hdl.handle.net/10316.2/38921

DOI: $\quad$ DOI:http://dx.doi.org/10.14195/978-989-26-0864-8_9

Accessed : $\quad$ 26-Apr-2023 11:17:10

A navegação consulta e descarregamento dos títulos inseridos nas Bibliotecas Digitais UC Digitalis, UC Pombalina e UC Impactum, pressupõem a aceitação plena e sem reservas dos Termos e Condições de Uso destas Bibliotecas Digitais, disponíveis em https://digitalis.uc.pt/pt-pt/termos.

Conforme exposto nos referidos Termos e Condições de Uso, o descarregamento de títulos de acesso restrito requer uma licença válida de autorização devendo o utilizador aceder ao(s) documento(s) a partir de um endereço de IP da instituição detentora da supramencionada licença.

Ao utilizador é apenas permitido o descarregamento para uso pessoal, pelo que o emprego do(s) título(s) descarregado(s) para outro fim, designadamente comercial, carece de autorização do respetivo autor ou editor da obra.

Na medida em que todas as obras da UC Digitalis se encontram protegidas pelo Código do Direito de Autor e Direitos Conexos e demais legislação aplicável, toda a cópia, parcial ou total, deste documento, nos casos em que é legalmente admitida, deverá conter ou fazer-se acompanhar por este aviso.

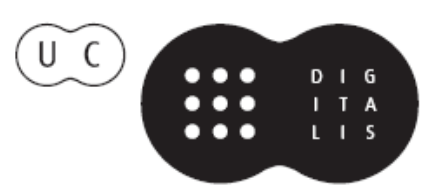




\section{GRAMÁTICA \\ DERIVACIONAL \\ DO PORTUGUÊS}

GRAÇA RIO-TORTO

ALEXANDRA SOARES RODRIGUES

ISABEL PEREIRA

RUI PEREIRA

SÍLVIA RIBEIRO

2. ${ }^{a}$ EDIÇÃO

IMPRENSA DA UNIVERSIDADE DE COIMBRA COIMBRA UNIVERSITY PRESS 


\section{CAPÍTULO 9. PROCESSOS DE CONSTRUÇÃO NÃO CONCATENATIVA}

M. Isabel P. Pereira

\subsection{Introdução}

A criação lexical em português, apesar de ser predominantemente concatenativa, dispõe de um conjunto de processos que não se enquadra nesse tipo de operações morfológicas. A "marginalidade" destes processos (cf. Alves 1990) pode atribuir-se quer à baixa frequência da sua utilização (sobretudo em português europeu), quando comparados com a afixação e a composição, quer a algumas das suas caraterísticas intrínsecas. Trata-se de operações que geram produtos através de mecanismos que não assentam em princípios de natureza eminentemente morfológica, mas antes de natureza fonológica/prosódica (cruzamento vocabular, truncação, reduplicação) e/ou gráfica (siglação/acronímia), em que estão envolvidos padrões não lineares de formação.

Nos produtos gerados através destas operações, não são identificáveis constituintes morfológicos encadeados linearmente, pois raramente as bases mantêm integralmente o seu material segmental ${ }^{117}$. Daí que diversos autores defendam que não se trata de processos de formação de palavras com estatuto morfológico.

117 Apenas nos casos de reduplicação total se pode assumir que as bases são preenchidas por palavras, pois todos os outros são processos que implicam mecanismos de supressão. 
Vistos por alguns autores como processos improdutivos (no sentido de Aronoff 1976) ${ }^{118}$, estão disponíveis em português, manifestam algumas regularidades notórias, não podendo, portanto, ser considerados imprevisíveis e aleatórios. Por outro lado, algumas das propriedades que os caraterizam são comuns a outras línguas em que também constituem mecanismos de criação lexical de uso mais restrito.

Com exceção da siglação, são processos mais frequentes no português do Brasil do que no português europeu, onde têm uma utilização muito restrita, particularmente a truncação e a reduplicação.

\subsection{Cruzamento vocabular}

\subsubsection{Definição}

O cruzamento vocabular ${ }^{119}$ pode ser definido como a junção de duas palavras existentes para formar uma palavra nova, com supressão de material segmental de pelo menos uma delas e, em certos casos, sobreposição de segmentos, como se pode observar em (1) e (2).

(1) brasiguaio (brasileiro + paraguaio)

cariúcho (carioca + gaúcho)

chafé (chá + café)

diciopédia (dicionário + enciclopédia)

118 O conceito de produtividade não suscita unanimidade entre os autores; daí que, para alguns (Araújo 2000, Basílio 2005 e 2010, por exemplo), as regularidades observadas nestes processos (ou, pelo menos, em alguns deles) e a frequência com que são usados na criação lexical em português (sobretudo no PB) os tornem processos produtivos.

119 Processo que surge na literatura também designado por amálgama, mistura, mescla lexical, portemanteau, mot valise (palavra valise), blend, entre outros. 
fabulástico (fabuloso + fantástico)

nim $(n \tilde{a} o+\operatorname{sim})$

portunhol (português + espanhol)

(2) apertamento (aperto + apartamento)

analfabruto $^{120}$ (analfabeto + bruto)

burrocrata (burro + burocrata)

meretríssimo (meretriz + meritíssimo)

pilantropia (pilantra + filantropia)

\subsubsection{Cruzamento vocabular e composição}

Os produtos do cruzamento vocabular, resultando da junção de duas bases lexicais, são considerados por alguns autores (Sandmann 1990, Araújo 2000, Basílio 2005) um tipo de composição em português. No entanto, são significativas as diferenças entre os dois processos de criação lexical (Rio-Torto 2014c):

i. a composição permite a junção de mais do que duas bases, enquanto os produtos de cruzamento vocabular atestados resultam da junção de apenas duas bases;

ii. nos compostos, as bases são preenchidas por constituintes morfológicos (radicais ou palavras); no cruzamento vocabular, como o conteúdo segmental das bases não é integralmente preservado ${ }^{121}$, não são reconhecíveis constituintes morfológicos;

120 Atestados também analfaburro e analfabesta.

121 A perda de material segmental nestes produtos não pode ser atribuída a processos fonológicos, como a crase ou a haplologia, que se observam nos compostos aguardente e dedurar (PB). 
iii. a composição preserva a sequencialidade linear dos constituintes; no cruzamento vocabular há rutura da sequencialidade linear, por meio de sobreposição;

iv. na composição (morfossintática) é preservada a estrutura prosódica de cada uma das bases, constituindo o composto um sintagma fonológico; o produto do cruzamento vocabular constitui uma única palavra fonológica, perdendo-se a estrutura prosódica dos seus componentes;

v. a composição é regida por princípios morfológicos ou morfossintáticos; o cruzamento vocabular obedece a certas condições prosódicas, pelo que é um processo que se situa na interseção da morfologia com a fonologia/prosódia.

Em síntese, as principais propriedades que distinguem os dois processos são aquelas que nos permitem dizer que a composição se insere na morfologia concatenativa, ao passo que o cruzamento vocabular não.

\subsubsection{Padrões de cruzamento vocabular}

Considerando aspetos estruturais, podem distinguir-se dois padrões diferentes de cruzamento vocabular (cf. Gonçalves 2003, 2006a, Gonçalves \& Almeida 2004):

i. formas em que não existe semelhança fónica entre as bases (1);

ii. formas em que existe semelhança fónica entre as bases e em que, consequentemente, se verifica sobreposição (2).

Os diferentes padrões de cruzamento vocabular determinam a forma de interseção das bases, nomeadamente a localização da segmentação de cada uma delas e o ponto de fusão entre as duas. 
No caso de bases monossilábicas (o número de exemplos atestados é reduzido), a segmentação faz-se entre o ataque e a rima, selecionando-se o ataque da primeira base e a rima da segunda, como se pode observar na representação:

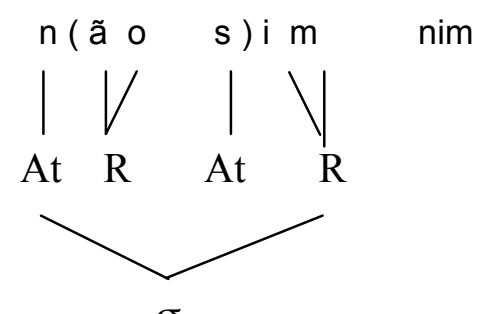

$\sigma$

Quando as bases são polissilábicas, a segmentação é feita na sílaba tónica, selecionando-se o material segmental pretónico de uma base, a sílaba tónica e o material segmental postónico da outra, como ocorre em portunhol:

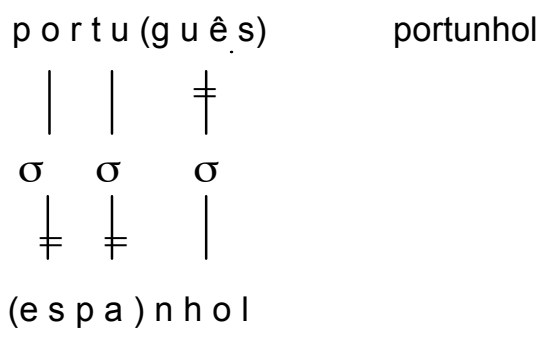

Em alguns produtos com bases sem semelhança fónica, a segmentação é feita no interior da sílaba tónica da base esquerda, circunscrevendo-se as sílabas pretónicas e o ataque da sílaba tónica da primeira base, a que se agrega a rima da sílaba tónica e as sílabas postónicas da segunda base, como em fabulástico. 


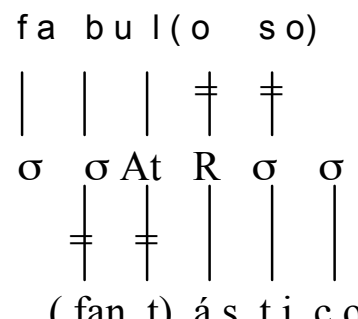

fabulástico

A seleção da ordem de ocorrência das bases no interior da forma complexa está dependente da recuperabilidade da identidade das bases. Um produto como *espaguês, por exemplo, seria opaco, tornando-se ininterpretável e, portanto, não cumpriria o seu objetivo comunicativo.

Já nos padrões em que existe semelhança fónica entre as bases (muito mais frequentes), a seleção, quer do ponto de segmentação, quer da ordem da sua ocorrência, é determinada pelo material segmental comum, como se pode verificar nos exemplos:

(3) analfabruto, tristemunho, meretríssimo

(4) pilantropia, pretoguês, exagelado

Nas formas de (3), o material comum às duas bases é reduzido, podendo consistir numa sílaba (tristemunho) ou num segmento (analfabruto $^{122}$ ). Nos exemplos de (4) a sequência segmental semelhante nas duas bases é muito maior, manifestando-se a diferença apenas numa sílaba (pretoguês) ou num constituinte silábico (pilantropia, exagelado $)^{123}$.

122 Neste exemplo, como em muitos outros, há um segmento comum no ponto de interseção das duas bases, mas há coincidência segmental também na sílaba final, o que faz com que apenas uma sílaba da base mais longa seja "estranha".

123 Basílio distingue cruzamento vocabular de fusão vocabular expressiva (que designa por fuve), definindo-a como "uma construção estruturada de modo 


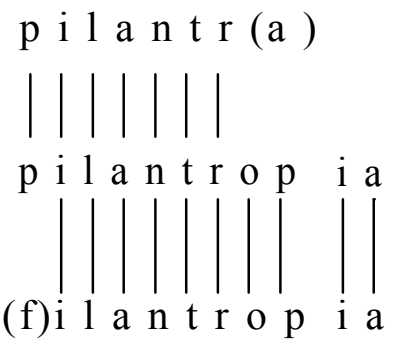

pilantropia

Nos produtos em que uma das bases é significativamente menor do que a outra (sobretudo quando a base menor é monossilábica ou bissilábica), verifica-se uma tendência para a preservação da estrutura da base menor, seja qual for a sua localização no interior da forma complexa - sempre determinada pela maior transparência da constituição interna do produto e consequente interpretação semântica ou pelo material segmental comum às duas bases -, como se pode observar nos exemplos (5)

(5) analfabruto, bicitáxi, boilarina, burrocrata, carnatal, futelama, pretoguês, prostiputa

\subsubsection{Aspetos sintático-semânticos}

A maioria dos produtos de cruzamento vocabular atestados é nominal ou adjetival, pertencendo, em geral, as bases à mesma categoria, que é também a categoria do produto, como se pode observar nos exemplos (1)-(5) ${ }^{124}$. Esse será o procedimento mais frequente

a incorporar fonologicamente os dois itens lexicais envolvidos, representando iconicamente a inclusão da função semântica do qualificador no significado da palavra base" (Basílio 2010: 202).

124 Dos exemplos apresentados, apenas nim pertence a outra categoria morfossintática (advérbio); no entanto, ambas as bases pertencem à mesma categoria 
de cruzamento vocabular, mas não há restrições no que respeita às categorias dos produtos, nem no que concerne às combinações categoriais. Combinatórias mais criativas e inesperadas encontram-se em obras literárias, como se pode observar, por exemplo, em textos de Guimarães Rosa (6) e de Mia Couto (7), autores conhecidos por explorarem a plasticidade da língua no que toca à criação vocabular.

(6) ferrabruto ([[ferrabrás $\left.\left.]_{\mathrm{N}}+[\text { bruto }]_{\mathrm{A}}\right]_{\mathrm{A}}\right)$ esquivançando $\left(\left[[\text { esquivar }]_{\mathrm{V}}+[\text { avançar }]_{\mathrm{V}}\right]_{\mathrm{V}}\right)$ estapaflorir ([[estapafúrdio $\left.\left.]_{\mathrm{A}}+[\text { florir }]_{\mathrm{V}}\right]_{\mathrm{V}}\right) 125$

(7) agradádiva $\left(\left[[\text { agradável }]_{\mathrm{A}}+[\text { dádiva }]_{\mathrm{N}}\right]_{\mathrm{A}}\right)$ escaravelhota $\left(\left[[\text { escaravelho }]_{\mathrm{N}}+\left[\text { velhota }_{\mathrm{A}}\right]_{\mathrm{A}}\right)\right.$ maisculino $\left(\left[[\text { mais }]_{\mathrm{Adv}}+\left[\text { masculino }_{\mathrm{A}}\right]_{\mathrm{A}}\right)\right.$ vislembrar $\left(\left[[\text { vislumbrar }]_{\mathrm{V}}+[\text { lembrar }]_{\mathrm{V}}\right]_{\mathrm{V}}\right)$

Nestes exemplos, encontram-se produtos verbais em que ambas as bases são também verbais (esquivançando, vislembrar) e outros em que as bases pertencem a categorias diferentes, sendo uma delas, obrigatoriamente, verbal (estapaflorir). Da mesma forma, encontramos produtos nominais e adjetivais constituídos por bases heterocategoriais, mas em que uma das bases pertence à mesma categoria do produto (agradádiva, ferrabruto).

Não é fácil estabelecer, de forma clara, classes de produtos de cruzamento vocabular com base em relações gramaticais entre os seus constituintes. Em alguns casos, podem identificar-se relações de coordenação, sobretudo quando os itens têm um cunho descritivo,

do produto. No exemplo pilantropia, não é relevante o facto de não estarmos perante duas bases da mesma classe morfossintática. Na verdade, pode-se conceber que o cruzamento resulta da interseção dos radicais complexos dos dois constituintes, uma vez que são possíveis também as formas pilantropo e pilantrópico.

125 Exemplos recolhidos em Carvalho 2008. 
o que ocorre geralmente (mas não exclusivamente) em formas em que não existe semelhança fónica entre as bases:

(8) abreijos, analfabruto, brasiguaio, cantriz, cantautor, diciopédia, fabulástico, nim, portunbol

(9) diligentil, ensimesmudo ${ }^{126}$

(10) abismaravilhado, cristalinda, curvilinda, desamimado, participassiva

Existem também produtos em que se reconhece uma relação atributiva clara:

(11) agradádiva, pirilimpo, maisculino ${ }^{127}$

Também em certas formas cruzadas em que há sobreposição das duas bases, como boilarina, lixeratura, namorido ou escaravelhota, se pode identificar uma relação atributiva, semelhante à que ocorre em compostos morfossintáticos de estrutura $\mathrm{N}+\mathrm{N}$, como palavra-chave. Porém, nas formas cruzadas, a localização do núcleo e do modificador pode variar: em boilarina e lixeratura, o modificador encontra-se à esquerda e o núcleo à direita; em namorido, 'namorado que tem comportamento de marido', e escaravelhota, a estrutura inverte-se.

Em grande parte dos casos em que há sobreposição das duas bases, nomeadamente naqueles em que a dissemelhança fónica é mínima, embora as estruturas se possam classificar como atributivas, a definição da relação gramatical entre as bases não é tão clara (como se verifica nos seguintes exemplos de Mia Couto: Sulplício, marmurar, telesféricos, reiclinado 128.

126 Exemplos de Guimarães Rosa, recolhidos em Carvalho 2008.

127 Exemplos (10) e (11) retirados de obras de Mia Couto.

128 Uma interpretação descontextualizada destas formas pode contrariar a afirmação feita, que tem em conta o uso destes termos no seu contexto de origem. 
A aproximação do cruzamento vocabular à composição, que alguns autores defendem, assenta parcialmente em razões de natureza semântica: tal como a composição, o cruzamento vocabular gera formas compósitas com uma significação única resultante da combinação das bases. No entanto, também neste aspeto se observam diferenças entre os dois processos.

A criação lexical por cruzamento é sempre intencional, os produtos «não são formações inocentes» (Basílio 2010: $204{ }^{129}$ ). A função expressiva deste processo de formação é um dos seus elementos caraterizadores. Daí que o uso de itens lexicais deste tipo se circunscreva a certos registos discursivos (semi-)informais, orais ou escritos, no âmbito jornalístico, literário, publicitário/propagandístico, político e humorístico.

O efeito humorístico é muito frequentemente o objetivo deste tipo de formas. Este efeito depende, em larga medida, da seleção das bases. No entanto, a natureza do próprio processo maximiza o impacto da combinação dos elementos selecionados. Nos produtos de cruzamento vocabular, o falante cria uma expectativa, que é quebrada num determinado ponto da cadeia fónica, causando estranheza; este processo é otimizado nas formas em que há sobreposição das bases, com dissemelhança fonológica mínima: uma sílaba ou um constituinte silábico preferencialmente preenchido apenas por um segmento. Para interpretar a forma cruzada, o falante tem de recuperar as duas bases na sua forma integral e criar um novo sentido para a forma complexa.

Os produtos de cruzamento são criados para diferentes finalidades: denominar novas realidades, sejam entidades (processo muito comum na criação de marcas de produtos comerciais, como

129 Esta afirmação é feita relativamente à "fusão vocabular expressiva", que a autora define como um tipo particular de cruzamento vocabular, mas pode aplicar-se a todos os produtos deste processo. 
em mentoliptus, diciopédia), sejam conceitos (franglês); exprimir uma avaliação (agradádiva). No entanto, estas formas têm uma particularidade: são criações de um sujeito falante que manifesta através delas um ponto de vista, criando uma realidade renovada (cf. Gonçalves \& Almeida 2004:148).

$\mathrm{Na}$ maioria das formas cruzadas, constrói-se uma estrutura semântica de qualificação, não raras vezes de caráter pejorativo. Nas formas em que a diferença fonológica é mínima (os produtos bem sucedidos, segundo Basílio 2005 e 2010), o qualificador é a forma "estranha" que se incorpora disfarçadamente na base hospedeira, o elemento qualificado. Assim, em pirilimpo, o constituinte hospedeiro é "pirilampo", sendo limpo o qualificador; em lixeratura, literatura é a base hospedeira, a que se incorpora "lixo".

A interpretação dos produtos de cruzamento vocabular não resulta exclusivamente de propriedades estruturais. Frequentemente, sobretudo no discurso jornalístico, publicitário, propagandístico e político, está dependente de informação contextual, seja de natureza política, cultural, geográfica ou histórica.

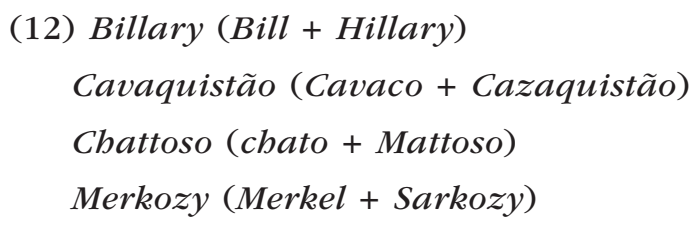

Os exemplos de (12) são opacos para muitos falantes do português e alguns deles, em voga no presente, sê-lo-ão inevitavelmente num futuro não muito longínquo, dada a referência específica a personagens de um momento histórico-político. Esta é uma peculiaridade deste tipo de produtos: são, quase sempre, efémeros. Quando, como nos casos de (12), são difundidos e partilhados numa comunidade, têm o tempo de vida da realidade que referem e a sua significação está muito dependente de informação contextual. 
Quando criados no contexto de uma obra literária, os cruzamentos têm, geralmente, uma utilização única. Nesse caso, a sua significação deve ser independente do contexto, para que possa ser interpretado adequadamente por qualquer falante-leitor, em qualquer contexto.

\subsection{Truncação}

\subsubsection{Definição}

A truncação, processo também designado truncamento, redução, encurtamento ou abreviação (clipping em inglês), pode ser definida como um processo de criação vocabular através do apagamento de material segmental de uma palavra-base, dando origem a uma forma diferente, que mantém, no entanto, o mesmo valor referencial. Sob esta definição, porém, pode abrigar-se um conjunto de processos redutivos em que operam princípios muito diferentes e que devem, por isso, ser considerados separadamente.

a) bora (<embora), cusco (<cuscovilheiro), china (<chinês), da-se $(<f o d a-s e)$, flagra (<fragrante), gorja (<gorjeta), neura (<neurose), mongo (<mongoloide), noia $(<$ paranoia $)$

b) anarca (<anarquista), boteco (<botequim), comuna (<comunista), estranja (<estrangeiro), emigra (emigrante), matrecos (<matraquilhos), proleta $(<$ proletário $)$, reaça $(<$ reacionário), salafra $(<$ salafrário $)$ 
(14) foto (<fotografia), mini, micro, estéreo (<estereofonia), otorrino (<otorrinolaringologista)

quimio (<quimioterapia), rádio (<radioterapia)

a) Bela, Beto, Chico, Lena, Lina, Mena, Nando, Nela, Tina, Tone

b) Bé, Lu, Nel, Quim, São, Tó, Zé

Nos exemplos (13) - (15), encontramos formas reduzidas que podemos distribuir por três grupos diferentes. Os exemplos de (13) obtêm-se através de mecanismos redutivos dependentes de princípios fonológicos, pois o material segmental apagado e o material segmental que se mantém não constituem unidades de nível morfológico; as formas de (14), sendo também geradas por redução, obedecem a princípios morfológicos: a sequência preservada constitui uma unidade morfológica da palavra-base e a segmentação é feita com base nessa identificação morfológica, mantendo-se a integridade segmental do constituinte. Estas palavras são sempre criadas a partir de formas morfologicamente complexas (sejam formadas por composição morfológica, sejam derivadas por prefixação). Esta é uma diferença fundamental entre os dois grupos ${ }^{130}$.

Um caso diferente é o que encontramos em (15). Nestas palavras, a redução assenta em princípios de natureza fonológica, o que as aproxima dos exemplos de (13), de que podem ser consideradas um subgrupo. Distinguem-se apenas pelo tipo de área lexical em que operam (hipocorísticos) e pelo facto de permitirem maior variação de padrões de redução.

130 Vilela, Godoy \& Cristófaro-Silva (2006) consideram dois processos diferentes: truncamento (formas de (13)) e redução vocabular (formas de (14)). Araújo (2002) designa as palavras reduzidas do grupo (14) (pseudo)truncamentos e exclui-as do escopo do processo de truncamento. 


\subsubsection{Padrões de truncação}

Nas formas truncadas do português podem observar-se algumas tendências de padrões de redução e de estrutura silábica e acentual do produto da redução. Em geral, podemos encontrar:

i.formas reduzidas bissilábicas;

ii.formas reduzidas trissilábicas.

As palavras truncadas bissilábicas, consideradas por certos autores como o padrão mais regular de truncamento (cf. Araújo 2002), são, em português europeu, paroxítonas. No português do Brasil, em que este processo é mais frequente, existem dois padrões acentuais de formas reduzidas bissilábicas: oxítonos (biju, deprê, profi, refrí) e paroxítonos.

A segmentação da forma de base para obtenção de formas reduzidas bissilábicas manifesta uma nítida tendência para a manutenção das duas sílabas do limite esquerdo e eliminação das restantes, sendo, geralmente, a palavra-base minimamente trissilábica (cusco, facho, flagra, gorja, monga, neura).

Os exemplos atestados de formas com truncação à esquerda são muito escassos (noia, da-se), o que comprova que esse não é um padrão "regular" na formação destes produtos.

As formas truncadas trissilábicas (13b) obedecem ao mesmo padrão de segmentação: truncação à direita e manutenção da sequência segmental da esquerda da palavra matriz. As formas resultantes do processo são paroxítonas.

Os produtos de truncação são nomes e adjetivos com o mesmo valor de género da palavra matriz. As formas (bissilábicas ou trissilábicas) mais frequentes são morfologicamente constituídas por um radical (a sequência segmental reduzida da palavra-base) e por um constituinte temático. $\mathrm{O}$ índice temático é normalmente $-a$, mas 
ocorre também -o (boteco, matrecos) e, em alguns casos (pouco frequentes), o índice temático pode variar em função do valor de género da palavra (facho/a, cusco/a). Algumas formas atestadas no português do Brasil são constituídas apenas por radical, sem constituinte temático (refrí, profí, biju, deprê ${ }^{131}$ ).

No que respeita a padrões acentuais, verifica-se que estas palavras observam rigorosamente as regularidades acentuais não marcadas, ou seja, são formas cujo acento recai sobre a sílaba que contém a última vogal do radical (cf. Pereira 1999). Todas as formas com índice temático são paroxítonas, as (raras) formas sem índice temático são oxítonas.

São usadas, no português europeu, palavras truncadas com formatos fonológicos irregulares, como os que se seguem:

\section{(16) fac, manif, prof 132}

Estas palavras não estão em conformidade com o mecanismo de truncação produtivo para o português, pois não possuem índice temático. Por outro lado, configuram uma irregularidade fonológica, por preencherem a coda com segmentos não permitidos neste constituinte silábico em português (o português do Brasil regulariza este tipo de sequências através da inserção paragógica da vogal [i]). É muito provável que estas formas tenham entrado na língua por empréstimo (possivelmente do francês, onde o processo de truncação é usado muito frequentemente).

Os produtos de truncação têm o mesmo valor referencial da palavra que lhes dá origem. A diferença entre as duas formas assenta, sobretudo, em aspetos de natureza discursivo-pragmática e sociolinguística. A utilização deste tipo de léxico restringe-se, em português,

131 Formas de origem: refrigerante, profissional, bijuteria, depressão/deprimido(a).

132 Formas de origem: professor, manifestação, faculdade. 
a registos informais orais e associa-se preferencialmente (mas não exclusivamente) a grupos etários mais jovens. Cinema, héli e pneu já são palavras comuns e desprovidas de marcas diastráticas ou diafásicas.

Certos autores atribuem a estas formas um sentido pejorativo, aproximando-as dos avaliativos (cf. Gonçalves 2006a). Em palavras como comuna, emigra, facho, mongo, proleta, reaça, podemos reconhecer essa valoração negativa, mas outros exemplos há que não podemos relacionar com uma modalização apreciativa desse tipo (fac, manif, matrecos, noia). No entanto, trata-se de formas com uma carga expressiva superior à das palavras-base e esse será o principal objetivo da sua construção.

\subsubsection{Hipocorização por truncação}

A truncação não é um processo de utilização frequente em português. A área de criação lexical em que é mais utilizado é a dos hipocorísticos. Na hipocorização, os padrões de truncação são um pouco diferentes e os mecanismos e princípios de seleção das sequências a manter e a apagar são mais variados do que na geração de outras formas.

(17) Bela (Anabela, Isabel), Berto (Alberto), Chico (Francisco), Lena (Madalena, Helena),

Mena (Filomena), Nela (Manuela), Nando (Fernando), Tina (Albertina, Valentina, Clementina...), Tone, Toni (António)

(18) Alex (Alexandre), Bia (Beatriz), Carol (Carolina), Dani (Daniel), Gabi (Gabriel), Isa (Isabel), Lili (Liliana)

(19) Bé (Isabel), Lu (Luísa), Né (Manuela), Nel (Manuel), Quim (Joaquim), Tó (António), São (Conceição), Zé (José) 
Podem reconhecer-se duas estruturas resultantes deste processo:

i.formas bissilábicas $(17,18)$;

ii.formas monossilábicas (19).

Nas formas bissilábicas encontramos dois padrões de seleção da truncação: apagamento à esquerda (17) e apagamento à direita (18). Quando as formas truncadas resultam da eliminação da sequência segmental do limite esquerdo da palavra-base, o ponto de segmentação é a sílaba tónica, que será também tónica na palavra truncada. Acentualmente, estes hipocorísticos são paroxítonos, respeitando as regras acentuais da língua: podendo ser analisadas como palavras com índice temático, o acento está localizado na última sílaba do radical (a exceção, nos exemplos dados, é Toni, gerada por truncação à esquerda, mas que é constituída apenas por um radical; daí ser oxítona, respeitando também as regras acentuais).

Os hipocorísticos criados por truncação à direita apresentam maior diversidade estrutural e resultam de diferentes processos de segmentação. Em todos os casos há um alinhamento com o limite esquerdo da palavra, circunscrevendo-se duas sílabas, que constituem a sequência segmental do produto. Geralmente, a segmentação respeita a integridade silábica da base. Nos exemplos dados, as formas Carol e Alex apresentam uma segmentação irregular, uma vez que o corte se localiza entre o ataque e a rima da terceira sílaba da base. São muito raros os casos atestados que exibem este padrão e há razões para crer que se trata de empréstimos e não propriamente de um caso de formação por truncação em português.

A estrutura acentual destas formas também é regular. Sempre que elas podem ser analisadas como estruturas morfológicas que incluem um índice temático (Isa, Bia), são paroxítonas. Quando se trata de estruturas que preenchem apenas o radical, são oxítonas. 
Os hipocorísticos monossilábicos são gerados por seleção da sílaba tónica e apagamento de todo o material segmental à sua esquerda e à sua direita, quando exista. Em alguns casos, cria-se uma sílaba inexistente na palavra original, quer por eliminação da coda (Bé), quer por reconstrução silábica (Né, Nel). As sílabas destas formas têm obrigatoriamente o ataque preenchido, razão pela qual é feita a ressilabificação quando a sílaba tónica da palavra matriz não tem ataque. Este procedimento facilita também a recuperação do nome original. No português europeu, os hipocorísticos monossilábicos apresentam tendencialmente uma estrutura silábica CV. Essa tendência não se verifica no português do Brasil, que mantém a estrutura da sílaba tónica selecionada e que constrói, preferencialmente, hipocorísticos monossilábicos quando a palavra matriz é um nome oxítono com sílaba tónica de rima complexa (Raquel > Quel; Miguel > Guel).

Os hipocorísticos são, por definição, palavras associadas à manifestação de afetividade. Não têm um valor referencial diferente da palavra original, que substituem em determinados contextos de uso.

\subsection{Reduplicação}

\subsubsection{Definição}

A reduplicação é um processo que consiste na repetição de uma sequência segmental para criar uma palavra nova, podendo essa transformação carrear diferentes tipos de significação: gramatical (no malaio, por exemplo, é uma forma de manifestação do plural) ou lexical.

Podem identificar-se dois tipos de reduplicação, considerando a quantidade de material segmental da base que é copiada: reduplicação 
total, quando a palavra-base é repetida; parcial, quando apenas o é uma parte da palavra-base.

Este processo reveste-se, em muitas línguas, de enorme complexidade. Resulta da interação entre fonologia e morfologia e tem sido um desafio para teorias fonológicas e morfológicas. Alguns linguistas concebem-no como um tipo de afixação, em que o afixo não é uma sequência segmental fixa, mas uma estrutura prosódica resultante de uma cópia melódica (cf. Marantz 1982).

Os itens lexicais em que, em português, se observa repetição de sequências segmentais, além de pouco frequentes, não manifestam todos o mesmo tipo de propriedades. Podemos distinguir vários grupos:

(20) Reduplicação total: assim-assim, bombom, cai-cai, corre-corre, doi-doi (dodoi), esconde-esconde, lufa-lufa, pula-pula, pisca-pisca

(21) Repetição parcial de uma base lexical identificada: titi (titio/a), vovó, vovô, papá (papai), mamã (mamãe)

(22) Hipocorização por reduplicação: Bebé, Fafá, Fifi, Gigi, Nené, Nonô, Sissi, Zezé

(23) Repetição onomatopaica: auau, memé, popó, tautau (tatau), reco-reco, zunzum

(24) Repetição de sílabas ou de sequências de sílabas sem ligação a uma base lexical identificável: cocó, pipi, ó-ó, bebé, babá, totó, xexé, gagá, chuchu, blablablá, lengalenga, truca-truca

As palavras exemplificadas em (23) e (24) não podem ser consideradas como resultado de um processo morfológico de reduplicação, uma vez que não são criadas a partir de uma base léxica. Frequentes, sobretudo, na linguagem infantil, estas formas têm uma forte carga expressiva, tal como os verdadeiros produtos de reduplicação. No entanto, a repetição fónica não passa de um 
recurso de ordem fonológica na constituição segmental do significante de itens lexicais morfologicamente simples (não se reconhece uma estrutura interna complexa nestes exemplos).

Assim, apenas as formas construídas através dos padrões de redobro identificáveis nos exemplos de (20), (21) e (22) podem ser consideradas como produtos de reduplicação.

\subsubsection{Padrões de reduplicação}

\subsubsection{Reduplicação total}

A reduplicação total consiste na cópia integral do material segmental da palavra-base; constitui o padrão mais frequente deste processo em português. Se excetuarmos os exemplos lufa-lufa, assim-assim e bombom, com estruturas $[\mathrm{N}+\mathrm{N}]_{\mathrm{N}}$, [Adv $\left.+\mathrm{Adv}\right]_{\mathrm{Adv}}$ $\mathrm{e}[\mathrm{A}+\mathrm{A}]_{\mathrm{N}}$, os produtos reduplicados através da aplicação deste modelo obedecem à estrutura $[\mathrm{V}+\mathrm{V}]_{\mathrm{N}}$. A forma verbal da base encontra-se, invariavelmente, na $3 .^{a}$ pessoa do singular do Presente do Indicativo.

(25) a) corre-corre, coça-coça, foge-foge, mata-mata, mexe-mexe, mija-mija, pisca-pisca, pula-pula, raspa-raspa

b) esconde-esconde, agarra-agarra, empurra-empurra

c) doi-doi, cai-cai

As bases destes itens são maioritariamente bissilábicas, mas não há restrições quanto ao número de sílabas da base, como se pode comprovar em (25).

$\mathrm{Na}$ reduplicação total, o constituinte prosódico copiado é a palavra prosódica, pelo que a estrutura acentual do reduplicante é 
idêntica à da base. Daí resulta que as formas reduplicadas tenham dois acentos, constituindo, assim, um sintagma fonológico.

As caraterísticas estruturais, quer morfológicas, quer prosódicas, destes produtos aproximam-nos dos compostos. No entanto, há diferenças observáveis entre os dois tipos de produtos:

i. existe uma regularidade semântica na construção do significado dos produtos de reduplicação que não se observa geralmente nos compostos;

ii. a relação semântica entre a base e o produto reduplicado não pode ser enquadrada no quadro tipológico dos compostos.

Como nos demais casos de composição que envolvem uma forma verbal, o produto $[\mathrm{VV}]_{\mathrm{N}}$ pertence a uma categoria diferente da das bases: a nominal (cf. um doi-doi, um corre-corre, o pára-arranca, o sobe-desce); assim não acontece com os compostos morfossintáticos coordenados em que não há constituinte verbal (cf. saia-casaco, outono-inverno, surdo-mudo), pois nestes casos a categoria do produto é a mesma que a dos núcleos ( $\mathrm{N}$ ou $\mathrm{A}$ ).

Nas sequências $[\mathrm{V}+\mathrm{V}]_{\mathrm{N}}$ de reduplicação total estabelece-se uma relação de coordenação (cf. cap. 7: 7.3), mas sob o ponto de vista semântico não há mera copulação do semantismo das bases, como em norte-sul, ou em para-arranca. Por força da reduplicação da base, os itens reduplicados exprimem, geralmente, iteratividade ou repetição, e cumprem também uma função expressiva. São palavras que designam atividades (corre-corre, empurra-empurra, mata-mata, truca-truca), objetos ou entidades associadas metafórica ou metonimicamente à repetição da ação do verbo da base (cf. cai-cai, pisca-pisca). Em muitos há uma clara cristalização do sentido final, que não se subsume na denotação literal das bases: doi-doi denota um ferimento, e é usado na interação com bebés; cai-cai denota um tipo de peça de roupa feminina que cobre o peito, sem 
alças nem mangas; pisca-pisca denota um 'dispositivo luminoso e intermitente que se coloca no cruzamento de vias perigosas ou que, nas viaturas, serve para assinalar mudança de direção'.

\subsubsection{Hipocorização por reduplicação}

A reduplicação parcial, em português, aplica-se, exclusivamente, na formação de hipocorísticos (exemplos de (21) e (22)). A forma reduplicada é criada por extração da sílaba tónica da base e redobro dessa sílaba, à esquerda da base, gerando sempre dissílabos. A evidência empírica da localização da reduplicação provém dos dados do português do Brasil, em que, além do padrão descrito, se encontram formas como titio/a, mamãe ou papai, em que se verifica uma simplificação da sílaba tónica da base no limite esquerdo da palavra.

Nas formas atestadas em português europeu, as sílabas - quer a da base, quer a do redobro - são sempre de estrutura CV, mesmo que, na palavra original, a sílaba tónica tenha outra estrutura. Por exemplo, em Nonô, hipocorístico de Leonor, e Bebé (hipocorístico de Isabel) as respetivas sílabas tónicas perdem a coda. No português do Brasil, como referido, há formas em que se mantém a estrutura, mais complexa, da sílaba da base, mas em que a sílaba duplicada obedece ao padrão CV. Verifica-se uma clara tendência para os padrões menos marcados da língua.

As estruturas reduplicadas segundo este padrão não têm índice temático e a estrutura acentual é regular: o acento encontra-se na última sílaba do radical, dando origem a palavras oxítonas.

A tendência, observável nestes produtos, para as estruturas mais regulares é contrariada apenas num aspeto: as vogais da sílaba átona destas formas não são afetadas pelos processos de redução (elevação e recuo) caraterizadores do vocalismo átono do português

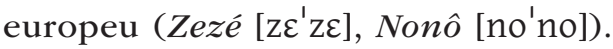


Os produtos de reduplicação parcial, sendo hipocorísticos, não têm um valor semântico referencial diferente da palavra original, de que são sinónimos, usados em contextos específicos.

\subsection{Siglação, Acronímia}

\subsubsection{Definição}

As siglas/acrónimos constituem parte importante da expansão vocabular atual, sendo comummente aceite que são criadas a partir de uma regra que estipula a extração da primeira letra de cada uma das palavras que constituem a expressão substituída/simplificada. A forma como se faz essa extração, no entanto, admite variações, sendo frequente a seleção de vários segmentos das bases para a constituição da sigla.

Há um elevado grau de imprevisibilidade nestes produtos, que certamente está na origem da falta de consenso em torno da definição de siglação e da dificuldade em estabelecer uma terminologia padronizada para estes processos redutivos de criação lexical. Um aspeto controverso reside precisamente na diferenciação entre sigla e acrónimo. Giraldo Ortiz (2010), partindo de uma revisão exaustiva da bibliografia de referência, apresenta uma proposta de definição e de classificação das siglas: «una sigla es una unidad de reducción formada por carateres alfanuméricos procedentes de una unidad léxica de estrutura sintagmática. Una sigla forma una secuencia cuya pronunciación puede ser alfabética, silábica o ambas» (Giraldo Ortiz 2010: 73).

Neste quadro classificatório, distinguem-se (i) siglas próprias e (ii) siglas mistas, cujas propriedades se sintetizam no quadro seguinte: 


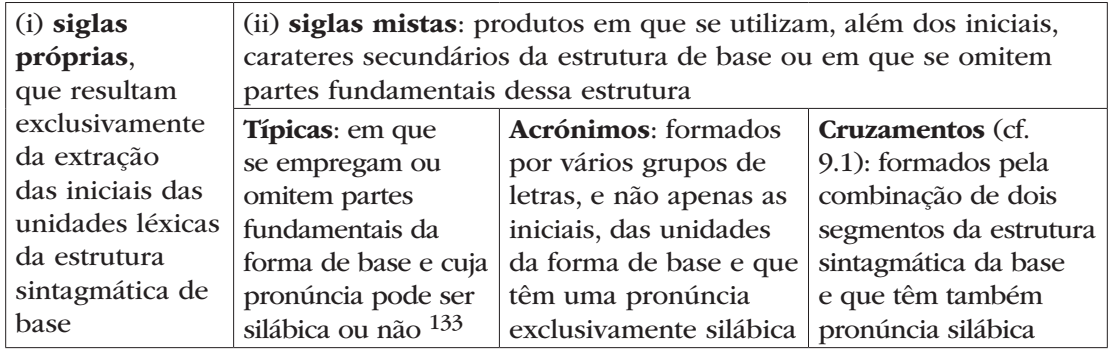

Quadro IX.1. Quadro classificatório de siglação, acronímia, cruzamento (baseado em Giraldo Ortiz 2010)

Trata-se de uma classificação que assenta na combinação de dois critérios: a forma como são criadas as unidades (que carateres se extraem da base) e a forma como são pronunciadas as unidades. Dessa combinação resulta uma tipologia em que "sigla" é um termo genérico para referir unidades lexicais reduzidas formadas a partir da forma gráfica de estruturas sintagmáticas e "acrónimo" um subtipo de sigla.

\subsubsection{Um processo morfológico?}

A siglação tem sido considerada por diferentes morfólogos como um processo de criação vocabular, mas não como um processo de formação de palavras (cf. Aronoff 1976, Spencer 1991, Aronoff \& Hanshen 1998, Haspelmath 2002, entre outros). Esta consideração fundamenta-se no facto de que se trata de um processo não regular e opaco, no sentido em que dá origem a palavras em que não se reconhece uma estrutura interna.

Há vários argumentos que sustentam o estatuto não morfológico da siglação ${ }^{134}$, entre os quais se destacam a sua não universalidade

133 Podem ser lidos silabicamente ou não: HUC 'Hospitais da Universidade de Coimbra', POUS 'Partido Operário de Unidade Socialista'.

134 Para uma revisão exaustiva desses argumentos, cf. Rosa 2009. 
e a sua intencionalidade. A siglação não é um processo universal porque não está disponível em todas as línguas. Sendo inegável a sua base gráfica, apenas as línguas com sistemas de escrita fonológicos podem fazer uso deste recurso, em particular aquelas que são representadas por sistemas alfabéticos (embora os sistemas silábicos também o permitam). Além disso, e pelo mesmo motivo, a criação de siglas só é acessível a falantes alfabetizados, com uma competência de escrita que inclua não só o conhecimento dos grafemas, mas também a capacidade de segmentação e de manipulação das cadeias gráficas.

Por outro lado, a siglação é um processo intencional. Há um elevado grau de liberdade na manipulação dos grafemas (daí a dificuldade de tipificação dos processos), geralmente com o objetivo de criar sequências eufónicas ou que possam ser associadas a outras unidades significativas da língua ${ }^{135}$.

A intencionalidade subjacente à criação de siglas, assente na manipulação, com acentuado grau de imprevisibilidade, das letras do sintagma original, faz com que não haja nos produtos elementos constantes, reconhecíveis pelos falantes como unidades significativas que podem ser reutilizadas para criação de novo léxico. Assim, o falante não pode usar o conhecimento linguístico para a criação de itens lexicais deste tipo, pelo que não podemos considerar a existência, neste domínio lexical, de palavras potenciais ${ }^{136}$. Apenas se pode falar de mecanismos (semi-)regulares de criação de sequências grafo-fónicas que podem ser articuladas como palavras. Por essa razão é considerado por muitos um processo improdutivo (na aceção

135 Em Rosa (2009: 53) são apresentados vários exemplos em que se procura criar uma forma que possa ser associada a uma raiz (MERCOSUL - Mercado Comum

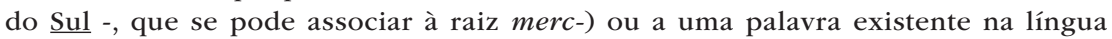
(GRUDA (Grupo de Estudos de Doenças Afectivas).

136 Apenas se pode falar de formas potenciais de criar sequências grafo-fónicas que podem ser articuladas como palavras. 
de Aronoff (1976) e Aronoff \& Anshen (1998)). Por isso também a generalidade dos morfólogos considera que não é um processo que se enquadre no escopo da morfologia «because the resulting new words do not show systematic meaning-sound resemblances as the sort that speakers would recognize» (Haspelmath 2002:25).

\subsubsection{Caraterísticas fonológicas}

Os produtos gerados por siglação são analisados pelos falantes como vocábulos da língua e, portanto, espera-se que obedeçam às suas regras fonológicas no que respeita a três aspetos: a estrutura acentual, a estrutura silábica e as regras que afetam os segmentos em contextos definidos.

\subsubsection{Estrutura acentual}

As formas que seguem as regras acentuais do português são dominantes. As siglas próprias (no sentido de Giraldo Ortiz (2010)), como são constituídas pela designação dos grafemas, têm uma estrutura acentual particular. Em formas como PCP [pese'pe] ou INH [iغne'ga] 137, cada constituinte mantém a sua proeminência acentual própria, funcionando a sigla como um sintagma fonológico, em que se reconhecem vários acentos e em que a proeminência principal se situa no limite direito, de acordo com as regras do português.

Nos casos em que a sigla tem uma pronúncia silábica, a sequência é analisada como uma palavra morfológica, com a respetiva constituição interna, e o acento (aqui representado por ' a anteceder

137 PCP (Partido Comunista Português); INH (Instituto Nacional da Habitação). 
sílaba tónica) é atribuído à sílaba que é analisada pelo falante como a última sílaba do radical. É o que ocorre nos seguintes exemplos ${ }^{138}$ :

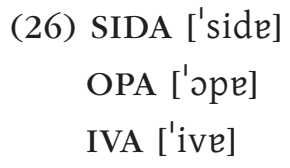

\author{
APAV [a'pav] \\ UNICER [uni'ser] \\ EPAL [ $\varepsilon^{\prime}$ pał $]$
}

Em palavras como SIDA, OPA, IVA, a vogal final é tratada como um índice temático e o acento é atribuído à sílaba anterior, que é analisada como a última do radical. Nos exemplos APAV, UNICER e EPAL, terminados em consoante, o falante identifica apenas um radical e atribui o acento à sua última sílaba. Temos, portanto, casos não marcados de acentuação.

Os casos marcados, embora raros, também ocorrem, como se pode observar em OVNI ['ovni].

\subsubsection{Estrutura silábica}

No que respeita à estrutura silábica, podemos também distinguir as formas em que a pronúncia é alfabética dos casos em que é silábica. Nos primeiros, que são constituídos pelas designações das letras, as sílabas têm estruturas não marcadas (V e CV), como nos exemplos:

(27) AVC [a.ve. 'se]

BCP [be.se. 'pe]

BI [be. 'i] 139

138 SIDA (síndrome de imunodeficiência adquirida), OPA (operação pública de aquisição), IVA (imposto sobre o valor acrescentado), APAV (Associação Portuguesa de Apoio à Vítima), UNICER (União Cervejeira), EPAL (Empresa Pública das Águas Livres).

139 AVC (acidente vascular cerebral), BCP (Banco Comercial Português), BI (bilhete de identidade). 
Nos acrónimos ou outros subtipos de siglas com pronúncia silábica, a silabificação pode gerar estruturas silábicas regulares, mais simples ou mais complexas (V, CV, CVC, CVV, CCVC) como em ${ }^{140}$

(28) BES ['bef]
JAE ['3aj]
CIMPOR [sĩ.'por]
ANACOM [e.ne.'kõ]
COI ['koj]

BEI ['bej]

AFI [a.'fi]

UNICER [u.ni.'ses]

No entanto, os casos em que se geram produtos com estruturas silábicas marcadas são percentualmente significativos. A irregularidade dessas estruturas pode dever-se a dois fatores: o preenchimento da coda ou o preenchimento de ataques ramificados.

As sílabas finais destas formas preenchem as codas com os segmentos [k], [p] e [v], que não são admitidos pelas regras de silabificação em português, segundo as quais apenas líquidas e sibilantes podem preencher codas.

Outra violação das regras de silabificação consiste, como referido, na presença de sequências consonânticas irregulares no interior do vocábulo. Os grupos consonânticos "proibidos" ocorrem no vocabulário regular da língua portuguesa, embora sejam pouco frequentes, tendo os falantes a consciência do seu estatuto marcado. É essa consciência que explica a existência de estratégias de regularização de sequências deste tipo, como, por exemplo, a inserção de uma vogal - [i] no Português do Brasil e [i] no Português Europeu

140 BES (Banco Espírito Santo), JAE (Junta Autónoma de Estradas), CIMPOR (Cimentos de Portugal), ANACOM (Autoridade Nacional de Comunicações), COI (Comité Olímpico Internacional), BEI (Banco Europeu de Investimento), AFI (Alfabeto Fonético Internacional), UNICER (União Cervejeira). 
- entre os segmentos consonânticos da sequência. Considerem-se alguns exemplos ${ }^{141}$ :

\author{
(30) SNESUP [sne.'sup] \\ ISCTE [if.'kte]
}

CNE ['kne]

SMTUC [sm.'tuk]

Sequências consonânticas como as que se observam nas formas em (30) são muito frequentes em produtos de siglação, o que mostra que, neste itens lexicais, se admitem mais facilmente estruturas irregulares do que nas outras palavras da língua. Esta constatação é confirmada pelo facto de que, estando disponível a pronúncia alfabética destes itens, a maioria dos falantes seleciona a pronúncia silábica, tratando-os como acrónimos ${ }^{142}$.

No PB, a estas formas são aplicadas, sem exceções, as mesmas regras que se aplicam às outras palavras da língua com estruturas irregulares do mesmo tipo: : inserção (epentética ou paragógica) de [i], do que resultam sequências regulares (USP ['uspi]; AIDS [ajd3is]).

\subsubsection{Processos fonológicos segmentais}

Também no que concerne à aplicação de regras fonológicas que afetam segmentos em alguns contextos, como as regras de elevação e centralização de vogais átonas que caraterizam o português europeu, as siglas apresentam uma maior percentagem de irregularidades. Com efeito, é mais frequente a não redução das vogais

141 SNESUP (Sindicato Nacional do Ensino Superior), ISCTE (Instituto Superior das Ciências do Trabalho e da Empresa), CNE (Comissão Nacional de Eleições), SMTUC (Serviços Municipalizados de Transportes Urbanos de Coimbra).

142 A variabilidade da pronúncia dos produtos de siglação com sequências fonemáticas irregulares é elevada e não estão completamente determinados os fatores que fazem com que os falantes optem por pronúncia silábica ou alfabética (cf. Viana et alii 1996 e Veloso 2007). 
átonas do que a aplicação das regras de redução, como facilmente se pode verificar.
(31) PALOP [pa'lop]
ANAREC [ana'rek]
ASDI [a $3^{\prime}$ di]
APAV [a'pav]

\author{
GEFAC [3ع'fak] \\ IPATIMUP [ipati'mup] \\ INATEL [ina'teł] \\ PRODEP [pro' $d \varepsilon p]^{143}$
}

A redução vocálica só se verifica regularmente na vogal átona final, que, como foi já referido, é analisada pelos falantes como um índice temático.

(32) IVA ['ive] NATO ['natu] CACE ['kasi] ${ }^{144}$

As outras regras contextuais da língua não são, em geral, violadas. As vogais que antecedem consoante nasal homossilábica são nasalisadas:
(33) ANACOM [a.na. 'kõ]
CIMPOR [sĩ'.por]

A lateral velariza em coda (no português do Brasil, semivocaliza):

(34) INATEL [ina'teł]

EPAL $\left[\varepsilon^{\prime}\right.$ pał $]$

As sibilantes sofrem os processos de palatalização e assimilação de vozeamento em coda:

143 PALOP (Países Africanos de Língua Oficial Portuguesa), ANAREC (Associação Nacional de Revendedores de Combustíveis), ASDI (Acção Social Democrata Independente), APAV (Associação Portuguesa de Apoio à Vítima), GEFAC (Grupo de Etnografia e Folclore da Academia de Coimbra), IPATIMUP (Instituto de Patologia e Imunologia Molecular da Universidade do Porto), PRODEP (Programa Operacional Educação).

144 CACE (Centro de Apoio à Criação de Empresas). 
Os hiatos que o permitem sofrem ditongação:
(36) COI ['koj]
JAE ['3aj]
BEI ['bej]

Considerando as caraterísticas fonológicas dos produtos de siglação, observamos que, se é certo que eles são percebidos e produzidos como se de palavras primitivas da língua se tratasse, é também notório que neles ocorrem mais violações das regras fonológicas e prosódicas e que os falantes parecem aceitá-las mais facilmente do que no restante léxico. O grau de aceitabilidade destas irregularidades permite-nos colocar a hipótese de um léxico estruturado em vários patamares (Itô e Mester 1999), em que as siglas estão distantes do núcleo constituído pelo vocabulário nativo. Neste léxico mais periférico são admissíveis mais comportamentos irregulares.

\subsubsection{Relação grafia - som}

A siglação produz itens lexicais que, tendo uma origem gráfica, têm uma forma fónica. A descrição dos aspetos fonológicos apresentada incide sobre a forma fónica resultante da leitura de sequências gráficas (os verdadeiros produtos deste mecanismo de criação vocabular). Sendo essa forma determinada pelo aspeto gráfico, ela obedece aos mecanismos de leitura condicionados pelas regras ortográficas da língua. Considerem-se os exemplos:

\section{(37) CACE ['kasi] ANAREC [ana'rek] GEFAC [3 $\varepsilon^{\prime}$ fak]}

Nestas formas, os grafemas $<\mathrm{c}>,<\mathrm{r}>$ e $<$ g $>$ representam um som diferente no sintagma original ([s], $[\mathrm{k}],[\mathrm{R}]$ e $[\mathrm{g}])$ e no acrónimo ([k], 
[s], [r] e [3] respetivamente), por efeito de regras de descodificação da grafia $(<\mathrm{c}>$ antes de $<\mathrm{e}>$, representa o som [s], antes de $<$ a $>$ representa o som $[\mathrm{k}] ;<\mathrm{r}\rangle$ entre vogais representa o som $[\mathrm{r}] ;<\mathrm{g}>$ antes de $<$ e $>$ representa o som [3]).

\subsubsection{Uso e comportamentos morfossintáticos}

A siglação é, no português atual, um processo muito frequente de criação vocabular, usado profusamente em linguagens especializadas e na denominação de organismos, instituições, empresas ou marcas comerciais e, por vezes excessivamente, no discurso mediático.

A língua portuguesa é muito permeável a empréstimos neste domínio lexical, onde formas como as de (38) são de uso corrente, tendo substituído, nos casos em que existem, as siglas correspondentes em português. O mesmo acontece com as já lexicalizadas formas de (39).

(38) NATO, UNICEF, UNESCO, UEFA, LSD, CEO, HIV, BSE, USB (39) radar, laser, spa

As siglas/acrónimos têm autonomia relativamente à expressão sintagmática que lhes dá origem, que, geralmente, não é recuperada pelo falante, mesmo que conheça o seu referente e/ou significa$\mathrm{do}^{145}$ (são formas verdadeiramente opacas, dado o mecanismo que as origina). Na maior parte dos casos, o seu uso suplanta o do sintagma-base, o que é compreensível, dado que se trata de uma simplificação muito mais económica.

Em certos casos, o falante analisa a sigla/acrónimo como uma palavra primitiva, muito particularmente (mas não exclusivamente)

145 Isso mesmo se verifica nos casos de empréstimo de siglas. 
quando a sua pronúncia é silábica. Dessa forma, ela passa a constituir base de processos morfológicos, seja de flexão, seja de derivação.

(40) TICs (țecnologias da informação e da comunicação)

PALOPs (países a fricanos de língua oficial portuguesa)

OVNIs (objetos voadores ñão ídentificados)

RFPs (regras de formação de palavras)

PMEs (pequenas e médias empresas)

A pluralização destas formas é muito frequente, apesar de algumas delas corresponderem a sintagmas cujo núcleo está já pluralizado ${ }^{146}$.

Alguns produtos de siglação podem constituir base de processos de derivação. Derivados como sidoso, ovnilogia (português europeu) ou peemedebismo ${ }^{147}$, otenização 148 (PB) são criados pelos falantes a partir de siglas, embora não sejam muito numerosas as que preenchem as bases em processos desta natureza.

A siglação produz nomes que, consequentemente, têm valor de género inerente. Geralmente, o valor de género do produto corresponde ao valor de género do núcleo do sintagma-base. No entanto, existem casos de hesitação na atribuição de género (o/a TAC). Da mesma forma, existem casos em que o valor de género é atribuído por uma motivação diferente, como se pode ver nos exemplos $a$ PT (Portugal Telecom), $a$ CIMPOR (Cimentos de Portugal), a CP (Comboios de Portugal). Nestas formas, o valor de género atribuído parece corresponder a empresa (ou palavra sinónima com o mesmo valor de género), uma vez que se trata de nomes de empresas.

146 Nestes casos, há variação na marcação do plural: certos falantes acrescentam a marca do plural à sigla, outros apenas marcam o determinante com o morfema de plural (ex.: as TIC).

147 De PMDB (Partido do Movimento Democrático Brasileiro). Cf. Alves 1990: 59.

148 De OTN (Obrigações do Tesouro Nacional). Cf. Alves 1990: 58. 